\title{
Comparison between use of combination of mifepristone and misoprostol versus misoprostol alone in the management of intrauterine fetal death
}

\author{
Sreeveena Talasani, Pran Hitha Venkamolla, Kalpana Betha*
}

Share India, Mediciti Institute of Medical Sciences, Ghanpur, Medchal Mandal and District, Hyderabad, Telangana, India

Received: 03 May 2018

Accepted: 29 May 2018

*Correspondence:
Dr. Kalpana Betha,
E-mail: kalpanabasany@gmail.com

Copyright: $($ ) the author(s), publisher and licensee Medip Academy. This is an open-access article distributed under the terms of the Creative Commons Attribution Non-Commercial License, which permits unrestricted non-commercial use, distribution, and reproduction in any medium, provided the original work is properly cited.

\begin{abstract}
Background: Intrauterine fetal death (IUFD) is estimated to occur in $1 \%$ of all pregnancies. The advent of prostaglandins has revolutionized the management of IUFD. There are limited studies using a combined regimen of mifepristone and misoprost for induction of labor in IUFD. Hence this study was undertaken to assess the efficacy and safety of combined regimen with misoprostol alone, in the management of IUFD.

Methods: This hospital based prospective study included 60 pregnant women with IUFD admitted at Mediciti Institute of Medical Sciences, during the period January 2015 to July 2016. An ultrasound scan was performed to confirm IUFD and localize the placenta. Women were divided alternatively into 2 groups with 30 in each group (group 1 - women received $200 \mathrm{mg}$ mifepristone orally followed by misoprostol after 24 hours \& in group $2,100 \mu \mathrm{g}$ misoprostol every 6 hourly for a maximum of 4 doses between gestational age 24-26 weeks, 25-50 $\mu \mathrm{g} 4$ hourly for a maximum of 6 doses beyond 26 weeks).

Results: The mean induction to delivery interval was 10 hours in group 1 and 16.3 hours in group 2 (p value 0.007 ). Mean dose of misoprostol required in group 1 was 1.87 and 2.67 in group 2 (p value 0.008). With respect to side effects, the two groups did not differ significantly.

Conclusions: The combined regimen was more effective than misoprostol for the induction of labour in IUFD, in terms of higher rate of successful delivery and shorter induction to delivery interval.
\end{abstract}

Keywords: Delivery interval, Intrauterine fetal death, Induction, Misoprostol, Mifepristone

\section{INTRODUCTION}

Intrauterine fetal death (IUFD) is one of the most devastating obstetric complication affecting over 3 million pregnancies per year throughout the world. ${ }^{1} \mathrm{~A}$ clinically accepted definition of IUFD is the death of a fetus at or after 20 weeks. $^{2}$ A number of maternal, placental and fetal conditions can result in fetal demise, but in about $25-35 \%$ of cases, the cause remains unknown. ${ }^{3}$ Pregnancy loss at any gestational age is emotionally disturbing. A clear management plan which includes induction of labor is necessary to reduce the psychological distress and sepsis. ${ }^{4}$ When rupture of fetal membranes occur the risk of intrauterine infection increase and if the dead fetus is retained in the uterus for long duration (more than 4 weeks) there is a time related risk of consumption coagulopathy. ${ }^{5}$ Induction of labour is an evidence based practice of obstetrics. Various methods have been tried in the management of IUFD. The advent of prostaglandins has revolutionized the management of IUFD. ${ }^{6,7}$ The therapeutic effect of prostaglandins is limited by its side effects. These side effects are 
dependent on the type of prostaglandin, route of administration and dose. Misoprostol, a synthetic analogue is widely used because of its low cost, ease of administration and stability at room temperature. ${ }^{8}$ Mifepristone is a synthetic steroid compound with antiprogesterone activity. It induces cervical ripening and increases uterine activity and leads to expulsion of fetus and is widely used for $1^{\text {st }} \& 2^{\text {nd }}$ trimester termination of pregnancy. ${ }^{9-13}$

The combination of mifepristone and misoprostol is well established in the management of early $1^{\text {st }}$ trimester of pregnancy. ${ }^{14,15}$ However, there are limited studies using a combined regimen for induction of labour in intrauterine fetal death. The RCOG guideline also highlighted the need for good quality studies to determine safe and effective methods for induction of labor in IUFD and the optimal dose of misoprostol according to gestational age.

This study compared the efficacy and safety of the combined regimen with mifepristone and misoprostol in the management of intra uterine fetal death.

The primary outcome measures were successful vaginal delivery, induction to delivery interval (first dose of misoprostol to complete delivery of fetus and placenta). The secondary outcomes measured were dose of misoprostol, complications and side effects of drugs.

\section{METHODS}

The present study was conducted at Mediciti Institute of Medical Sciences, a rural tertiary teaching hospital, Telangana State, India from January 2015 to July 2016. Sixty pregnant women admitted with intrauterine fetal death were interviewed and examined clinically. An ultrasound scan was performed to confirm IUFD and localize the placenta.

The study was approved by the Institutional Ethics Committee. Data was collected using a pre tested proforma meeting the objectives of the study with their consent. Patient's demographic details were collected. Gestational age at presentation was determined preferably by first trimester scan. If a first trimester scan was not available, then menstrual dating and/or a second trimester scan was considered. Inclusion criteria included women with IUFD confirmed by ultrasound, women who gave consent for medical management, women not in labor, women with IUFD with congenital fetal anomalies. Exclusion criteria were multiple pregnancy with one intrauterine fetal death, grand multipara, scarred uterus, women who have contraindications to vaginal delivery, women with heart disease, glaucoma, epilepsy and bronchial asthma. Structured history followed by general physical, systemic and obstetric examination was carried out. An ultrasound scan was performed to confirm IUFD and localize the placenta. Complete blood picture, prothrombin time (PT), activated partial thromboplastin time (APTT), serum fibrinogen were measured when required. Eligible women were informed regarding details of the study protocol, alternative methods, and the adverse effects of the drugs. Assessment of the cervix was based on Bishop score. Women were divided alternatively into 2 groups with 30 in each group.

\section{Group I (combination regimen)}

Women received $200 \mathrm{mg}$ mifepristone orally followed by misoprostol after $24 \mathrm{hrs}$. Between gestational age 24- 26 weeks, women were induced with $100 \mu \mathrm{g}$ of misoprostol every 6 hourly for a maximum of 4 doses. Beyond 26 weeks, women were induced with $25-50 \mu \mathrm{g}$ of misoprostol every 4 hourly for a maximum of 6 doses.

\section{Group II (misoprostol alone group)}

Between gestational age 24-26 weeks, women were induced with $100 \mu \mathrm{g}$ of misoprostol every 6 hourly for a maximum of 4 doses. Beyond 26 weeks, women were induced with $25-50 \mu \mathrm{g}$ of misoprostol every 4 hourly for a maximum of 6 doses.

Subsequent to misoprostol administration, vital signs and progress of labor were recorded in modified World Health Organization (WHO) partographs. Active management of third stage of labor was performed. Any adverse events, such as postpartum hemorrhage or retained placenta, were recorded. Per vaginal examinations were kept to the minimum. Analgesics were restricted to those women who had intolerable pain. Oxytocin was used for augmentation of labor if required. Successful treatment was defined as delivery within 72 hours of $1^{\text {st }}$ misoprostol dose in both the groups.

The primary outcome measures were successful vaginal delivery, induction to delivery interval (first dose of misoprostol to complete delivery of fetus and placenta).The secondary outcomes measured were dose of misoprostol, complications and side effects of drugs. Adverse effects like hyperthermia, nausea, diarrhoea were recorded in both the groups.

\section{RESULTS}

In this observational study, a consecutive series of 60 pregnant women with IUFD were divided alternatively into 2 groups of 30 each during the period January 2015 to July 2016. Table 1 shows baseline characteristics and treatment regimens. In both the groups, majority of the patients $(85 \%)$ were unbooked $(86.7 \%$ in group 1 and $83.3 \%$ in group 2). Loss of fetal movements was the most frequent complaint in both the groups with $86 \%$ and $73 \%$ in group 1 and 2 respectively. Few of the patients had associated co-morbid conditions. Fifty percent of patients were anaemic, as majority of the patients belonged to low socioeconomic status. The mean hemoglobin in group 1 was $9.8 \mathrm{gm} \%$ and in group 2 was $10 \mathrm{gm} \%$. Only $23.3 \%$ in 
group 1 and $16.7 \%$ in group 2 had gestational hypertension. Almost all patients had unfavourable cervix in both the groups. The induction to delivery interval is the time interval between first dose of misoprostol to delivery of fetus in both the groups. The mean induction to delivery interval in group 1 was 10 hours and in group 2 it was 16.3 hours $(\mathrm{p}=0.007)$. Induction to delivery interval was significantly less in group given mifepristone. All women delivered vaginally in both the groups. The mean induction to delivery interval was less in group 1 in comparison to group 2 in women with both unfavourable and favourable cervix $(p=0.04)$. As the gestational age increased, induction to delivery interval was shortened in group 1 from 10.6 hours (24-28 weeks) to 9.5 hours (37-40 weeks) whereas in group 2 induction to delivery interval progressively increased from 24 weeks to 40 weeks. Majority of cases in group 1 were between 24-27 gestational weeks in group 1 in contrast to group 2 where the majority belonged to 32-35 gestational weeks. The average number of misoprostol required was 1.87 and 2.67 in group 1 and 2 respectively $(\mathrm{p}=0.008)$. The cumulative dose of misoprostol required in group 1 was $1325 \mathrm{~g}$ and in group 2 was $1450 \mathrm{~g}$. When induction delivery interval was compared in both the groups with respect to parity, gestational age and Bishop score, it was similar in primigravida whereas in multigravida it was long. Between 29-36 weeks gestational age, induction delivery interval was 12.4 hours and 17.3 hours in group 1 and 2 and the difference was statistically significant and with respect to Bishop score, there was no significant difference.

Table 1: Baseline characteristics of women and comparison of efficacy of both regimens.

\begin{tabular}{|llllll|}
\hline Baseline characteristics & Group 1 & & Group 2 & ANOVA \\
Age (years) & Average & SD & Average & SD & test \\
\hline Gestational age (weeks) & 23.3 & 3.43 & 23.30 & 3.37 & $\mathrm{p}=0.98$ \\
\hline Gravida & 30.10 & 4.30 & 30.97 & 4.41 & $\mathrm{p}=0.44$ \\
\hline Parity & 2.33 & 1.27 & 1.77 & 1.01 & $\mathrm{p}=0.06$ \\
\hline Bishop score & 1.00 & 0.95 & 0.47 & 0.68 & $\mathrm{p}=0.015(\mathrm{~S})$ \\
\hline Induction to delivery interval (hours) & 2.70 & 1.12 & 3.07 & 1.20 & $\mathrm{p}=0.22$ \\
\hline No. of doses of misoprostol required & 10.00 & 8.38 & 16.30 & 9.24 & $\mathrm{p}=0.007(\mathrm{~s})$ \\
\hline Birth weight (grams) & 1.87 & 1.20 & 2.67 & 1.06 & $\mathrm{p}=0.008(\mathrm{~s})$ \\
\hline Dose of misoprostol in micrograms & 1056.67 & 751.47 & 1311.67 & 780.80 & $\mathrm{p}=0.202$ \\
\hline
\end{tabular}

\section{DISCUSSION}

The study was carried out in a rural tertiary teaching hospital. Eighty five percent of the women were unbooked in both the groups. This necessitates the importance of early booking of antenatal women, identify high risk pregnancies, address them to prevent complications like IUFD. The mean age of the women was 23.3 \pm 3.43 years in combined group and 23.3 \pm 3.37 years in misoprost group, which was comparable to Chaudhuri et al study where mean maternal age in group 1 was $24.5 \pm 5$ years and $23.3 \pm 3.8$ years respectively. ${ }^{16}$

The present study included women with IUFD after 24 weeks of gestational age. The mean maternal age was 30 weeks in both the groups. In Fairley et al study also, the mean gestational age was 31 weeks in both the groups. Women with IUFD presents with decreased perception or loss of fetal movements in as many as $50 \%$ of cases. ${ }^{17}$ Others present with unexpected finding at a routine ultrasound or antenatal visit or with signs of an acute event such as abruptio placenta. In the present study, the mean induction to delivery interval in group 1 was 10 hours and in group 2 it was 16.3 hours while in Fairley et al study, the mean induction to delivery interval was comparatively low, which was 7 hours in combination group and 10.2 hours in group $2 .{ }^{17}$ Misoprostol $400 \mu \mathrm{g}$ vaginally was used followed by $400 \mu \mathrm{g}$ oral misoprostol in group 1 and $50 \mu \mathrm{g}$ of misoprostol vaginally 4 doses in group 2. In the present study, number of misoprostol doses required in group 1 and group 2 was 1.87 and 2.67 respectively $(\mathrm{p}=0.008)$. In Gupta et al study, the number of doses of misoprost to achieve successful vaginal delivery was higher in both the groups 2.9 and 4.2 in group 1 and 2 respectively. ${ }^{18}$

The regimen used in the present study caused mild gastrointestinal side effects like nausea, vomiting, diarrhoea in $6.7 \%$ of causes in group $1,13.4 \%$ in group 2 and Wagarachhi et al study too had similar rates of gastrointestinal side effects $(7.2 \%$ of cases in combination group). ${ }^{19}$ While Fairley et al reported high rate of gastroenteritis in $4.8 \%$ of women in group 1 and $35 \%$ in group $2 .{ }^{17}$ These side effects are attributed to the dose of misoprostol and route of administration. Complications like uterine tachysystole or hyperstimulation were not encountered as women were closely monitored after induction. Though the combination regimen is expensive than misoprost alone, given the low induction to delivery interval, low 
incidence of side effects, the combination regimen is safe and effective. The strengths of the study were that it was a prospective and comparative study and all women were admitted in both the groups and closely monitored for adverse effects. The limitations being, the sample size was small, women with scarred uterus were excluded and the interval between mifepristone and misoprostol was disadvantageous from psychological point of view.

\section{CONCLUSION}

For the induction of labor in IUFD after 20 weeks, the combination of mifepristone and misoprostol is a safe and effective method. It has a higher rate of successful delivery, shorter induction to delivery interval, better side effect profile.

Funding: No funding sources

Conflict of interest: None declared

Ethical approval: The study was approved by the Institutional Ethics Committee

\section{REFERENCES}

1. Chittacharoen A. A randomized trial of oral \& vaginal misoprostol to manage delivery in cases of fetal death obsetgynaecol. 2003;101(1):70-3.

2. ACOG practice bulletin No.102: Management of stillbirth. Obstet Gynecol. 2009;113:748-61.

3. Dutta DC. Preterm labour, preterm rupture of the membranes, post maturity, Intrauterine death of fetus. In: Konar H, editor. Text book of obstetrics including perinatology and contraception. 6th ed. Vol.21. Calcutta: New Central Book Agency (P) Ltd; 2004: 314-326.

4. ParasnisH, Raje B, Hinduja IN. Relevance of plasma fibrinogen estimation in obstetric complications. J Post grad Med. 1992;38:183-5.

5. Pritchard JA. Fetal death in utero. Obstet Gynecol. 1959;14:573-80.

6. Kochenour NK. Management of fetal demise. Clin Obstet Gynecol. 1987;30(2):322-30.

7. Fletcher HM, Wharfe G, Simeon D, Mitchell S, Brown D. Induction of labor with intravainal misoprostol versus dinoprostone in intrauterine death: a retrospective study. J Obstet Gynaecol. 1996; $16: 155-8$

8. Ngai SW, Tang OS, Ho PC. Prostaglandins for induction of second - trimester termination and intrauterine death. Best Pract Res Clin Obstet Gynecol. 2003;17(5):765-75.

9. Loose DS, Stancel GM. Estrogens and progestins. In: Goodman \& Gilman's the pharmacological basis of therapeutics. 11th ed. New York: McGraw Hill; 2006: 1541-1572.

10. Jang GR, Benet LZ. Antiprogestin pharmacodynamics, pharmacokinetics and metabolism: implications for their long term use. J Pharmacokinet Biopharm. 1997;25:647-72.

11. Robbins A, Splitz IM. Mifepristone: Clinical pharmacology. Clin Obstet Gynecol. 1996;39(2):436-50.

12. Ngoc NT, Shochet T, Raghavan S, Blum J, Nga NT, Minh NT, et al. Mifepristone and misoprostol compared with misoprostol alone for secondtrimester abortion: A randomized controlled trial. Obstet Gynecol. 2011;118:601-8.

13. Nagaria T, Sirmor N. Misoprostol vs mifepristone and misoprostol in second trimester termination of pregnancy. J Obstet Gynecol India. 2011;61:659-62.

14. Ashok PW, Flett GM, Templeton A. Effective, lowcost regimens for medical termination of pregnancy at all gestations. Contemp Rev Obstet Gynaecol. 1999;11:207-12.

15. Ashok PW, Penney GC, Flett GM, Templeton A. An effective regimen for early medical abortion: a report of 2000 consecutive cases. Hum Reprod. 1998;13(10):2962-5.

16. Chaudhuri P. Mandal A, Das C, Mazumdar A. Dosing interval of 24 hours versus 48 hours between mifepristone and misoprostol administration for mid trimester termination of pregnancy. Int $\mathbf{J}$ Gynaecol Obstet. 2014;124:134-8.

17. Fairley TE, Mackenzie M, Owen P, Mackenzie F. Management of late intrauterine death using a combination of Mifepristone and misoprostol experience of two regimens. Eur J ObstetGyn RB. 2005;118:28-31.

18. Gupta S, Kagathra B, Desai A. Mifepristone and misoprostol versus group2 in management of late intrauterine fetal death. Int $\mathrm{J}$ Reprod Contracept Obstet Gynecol. 2016;5(9):293.

19. Wagaarachchi PT, Ashok PW, Narvekar NN, Smith NC, Templeton A. Medical management of late intrauterine death using a combination of mifepristone and misoprostol. Br J ObstetGynaecol. 2002;109:443-7.

Cite this article as: Talasani $\mathrm{S}$, Venkamolla $\mathrm{PH}$, Betha K. Comparison between use of combination of mifepristone and misoprostol versus misoprostol alone in the management of intrauterine fetal death. Int J Reprod Contracept Obstet Gynecol 2018;7:2778-81. 